Article

\title{
Enhanced Antioxidant Activity under Biomimetic Settings of Ascorbic Acid Included in Halloysite Nanotubes
}

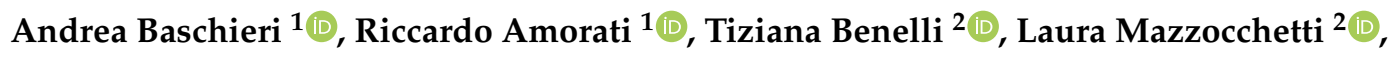 \\ Emanuele $D^{\prime}$ Angelo ${ }^{2}$ and Luca Valgimigli ${ }^{1, *(D)}$ \\ 1 Department of Chemistry “G. Ciamician”, University of Bologna, Via S. Giacomo 11, I-40126 Bologna, Italy; \\ andrea.baschieri2@unibo.it (A.B.); riccardo.amorati@unibo.it (R.A.) \\ 2 Department of Industrial Chemistry “Toso Montanari”, University of Bologna, Viale Risorgimento 4, \\ I-40136 Bologna, Italy; tiziana.benelli@unibo.it (T.B.); laura.mazzocchetti@unibo.it (L.M.); \\ emanuele.dangelo2@unibo.it (E.D.) \\ * Correspondence: luca.valgimigli@unibo.it; Tel.: +39-051-209-5683
}

Received: 31 December 2018; Accepted: 24 January 2019; Published: 27 January 2019

check for updates

\begin{abstract}
Antioxidant activity of native vitamin $\mathrm{C}$ (ascorbic acid, $\mathrm{AH}_{2}$ ) is hampered by instability in solution. Selective loading of $\mathrm{AH}_{2}$ into the inner lumen of natural halloysite nanotubes (HNT) yields a composite nanoantioxidant $\left(\mathrm{HNT} / \mathrm{AH}_{2}\right)$, which was characterized and investigated for its reactivity with the persistent 1,1-diphenyl-2-picrylhydrazyl (DPPH•) radical and with transient peroxyl radicals in the inhibited autoxidation of organic substrates, both in organic solution (acetonitrile) and in buffered ( $\mathrm{pH}$ 7.4) water in comparison with native $\mathrm{AH}_{2}$. HNT/ $\mathrm{AH}_{2}$ showed excellent antioxidant performance being more effective than native ascorbic acid by $131 \%$ in acetonitrile and $290 \%$ (three-fold) in aqueous solution, under identical settings. Reaction with peroxyl radicals has a rate constant of $1.4 \times 10^{6} \mathrm{M}^{-1} \mathrm{~s}^{-1}$ and $5.1 \times 10^{4} \mathrm{M}^{-1} \mathrm{~s}^{-1}$, respectively, in buffered water $(\mathrm{pH} 7.4)$ and acetonitrile, at $30{ }^{\circ} \mathrm{C}$. Results offer physical understanding of the factors governing $\mathrm{HNT} / \mathrm{AH}_{2}$ reactivity. Improved performance of $\mathrm{HNT} / \mathrm{AH}_{2}$ is unprecedented among forms of stabilized ascorbic acid and its relevance is discussed on kinetic grounds.
\end{abstract}

Keywords: halloysite; nanotube; nanoantioxidant; ascorbic acid; vitamin C; stability; antioxidant; peroxyl radicals; rate constant; biomimetic

\section{Introduction}

L-Ascorbic acid $\left(\mathrm{AH}_{2}\right)$ is, possibly, the most important water-soluble radical-trapping antioxidant in biological systems [1,2]. Unlike other animals, humans cannot biosynthesize it from glucose due to inactivation of the gene encoding the enzyme L-glucono- $\gamma$-lactone oxidase; therefore, ascorbic acid is an essential nutrient, known as vitamin C [3]. The recommended daily allowance (RDA) is $75 \mathrm{mg} /$ day for women and $90 \mathrm{mg} /$ day for man, however, its high-dose intake is considered safe up to $2000 \mathrm{mg}$ /day [4-7]. Following isolation in 1928, its fundamental biological function became progressively clear, starting from the prevention of scurvy [8]. Ascorbic acid is essential to the biosynthesis of collagen and other biomolecules, and it also protects from several chronic diseases including neurodegenerative conditions, heart disease, eye disease, and can serve as an adjuvant in the treatment of cancer [8,9]. Emerging evidence highlights its role in regulating the epigenome [10]. Although its role is not limited to being an antioxidant, arguably its antioxidant activity and its redox properties are key to its overall biological function [1-6,11]. Water solubility is, however, not less important. For instance, it enables the repair (regeneration) of lipid-soluble tocopherol (vitamin E) from its phenoxyl radical at the water-lipid interface in biomembranes and lipoproteins, thereby "exporting 
the unpaired electron" from the lipid phase into the aqueous phase [12] and preventing so-called tocopherol-mediated peroxidation (TMP) [13].

Despite its importance as a biological antioxidant, the use of ascorbic acid for the protection of any kind of man-made material or for other biomedical applications, such as the use in cosmetic and dermatological formulations, has been abandoned due to its major instability [14,15]. Indeed, even the degradation (firstly oxidative, secondly hydrolytic) of naturally occurring vitamin $C$ in fresh fruit and fruit juice upon storage is a current matter of major concern [16,17]. Due to its instability, the antioxidant activity of ascorbic acid can vary from excellent [18] to negligible [19], depending on the experimental conditions. To overcome this limitation a variety of derivatives of ascorbic acid have been proposed and have replaced it for different uses, although none appears as the ideal substitute. For instance, ascorbyl-2-glucoside [20] and sodium (or magnesium) ascorbyl phosphate [21] are obtained by blocking the $\mathrm{OH}$ group in position 2, thereby altering the redox properties of the molecule: while this approach guarantees higher oxidative stability and preserves water solubility, it also impairs the antioxidant activity, until enzymatic or spontaneous hydrolysis releases back the native ascorbic acid. As an alternative approach, esterification of ascorbic acid in position 6 (or 5) with lipophilic fatty acids, such as in ascorbyl palmitate or stearate maintains good antioxidant activity [22] while improving stability [23]; however, stabilization relies on transferring the molecule from the aqueous phase - where it can dissociate to ascorbate $\left(\mathrm{p} K_{\mathrm{a}}=4.17\right)$ becoming more reactive- - to the lipid phase, by making it lipophilic, hence, profoundly altering its role. Other proposals like ascorbyl tetraisopalmitate combine both approaches [24]: they guarantee higher stability but they also sum-up the limitations.

In the light of the above considerations, non-covalent stabilization of ascorbic acid by inclusion in inert nanocarriers appears as an interesting alternative.

Nano-encapsulation of ascorbic acid in liposomes [25] and in porous silica nanoparticles [26] has been reported, these last affording improved stability [26], although actual antioxidant activity of these hybrid materials was not investigated.

Halloysite (HNTs) is a natural nanotubular clay with typical length of $800 \mathrm{~nm}$ and external diameter of $80 \mathrm{~nm}$, composed of aluminosilicate and expressing (acidic) siloxane groups on the outer surface and (basic) aluminol at the inner surface. The difference between inner and outer surface allows different selectivity for molecules to be absorbed or linked in either surface [27-30]. Antioxidants loading on inner lumen has previously been reported in the case of a diarylamine for rubber stabilization [30], and in the case of natural phenolic antioxidants such as curcumin, silibinin [31], resveratrol [32], and quercetin [33] to obtain controlled antioxidant delivery systems.

Being water dispersible and non-toxic [34], HNT appeared optimal for protecting ascorbic acid in the inner cavity, so to create a fully biocompatible nanoantioxidant. The aim of this investigation was to assess whether inclusion of unstable ascorbic acid can improve its modest antioxidant performance under biomimetic settings and open new possibilities for unleashing its potential as an antioxidant. Preparation and properties of $\mathrm{HNT} / \mathrm{AH}_{2}$ will be presented along with a detailed investigation on its reactivity with alkylperoxyl radicals and DPPH•, both in organic medium and in buffered water solution, by testing the protection of standard oxidizable materials through controlled autoxidation studies [35-38]. Kinetic measurements will show, for the first time, improved antioxidant performance of $\mathrm{HNT} / \mathrm{AH}_{2}$ compared to the native material, whose physical-chemical understanding highlights the advantages of the proposed approach and paves the way to the rational development of even better biomimetic antioxidant materials.

\section{Materials and Methods}

\subsection{Chemicals and Reagents}

Ascorbic acid, AIBN (2,2'-azobis (2-methylpropionitrile)), AAPH ((2,2'-azobis (2-methylpropionamidine) dihydrochloride), PMHC (2,2,5,7,8-pentamethyl-6-chromanol), DPPH• (2,2-diphenyl-1-picrylhydrazyl), Chelex ${ }^{\circledR} 100$ sodium form, cumene, styrene, and tetrahydrofuran 
(unstabilized) were commercially available (Sigma-Aldrich, Milan, Italy). Solvents were HPLC or spectrophotometry grade and were used without further purification. THF was distilled under vacuum and stored under argon at $5{ }^{\circ} \mathrm{C}$; the content in hydroperoxides was $<50 \mathrm{ppm}\left(\mu \mathrm{g} \mathrm{g}^{-1}\right)$, as determined spectrophotometrically $(262 \mathrm{~nm})$ by detection of $\mathrm{Ph}_{3} \mathrm{P}=\mathrm{O}$ after titration with triphenylphosphine $\left(\mathrm{Ph}_{3} \mathrm{P}\right)$ in iso-propanol. Cumene and styrene were percolated through silica and through activated alumina to remove traces of peroxides and were stored under nitrogen. AIBN was recrystallized from methanol and stored at $-18{ }^{\circ} \mathrm{C}$. Halloysite nanoclay was purchased from Sigma-Aldrich: it had an average tube diameter of $70 \mathrm{~nm}$ and inner lumen diameter of $15 \mathrm{~nm}$. Typical specific surface area of this halloysite is $65 \mathrm{~m}^{2} \mathrm{~g}^{-1}$, pore volume of $\sim 1.25 \mathrm{~cm}^{3} \mathrm{~g}^{-1}$, refractive index 1.54 , and specific gravity $2.53 \mathrm{~g} \mathrm{~cm}^{-3}$.

\subsection{Buffer Preparation}

Buffers were freshly prepared with bidistilled water and were stored in a refrigerator. The $\mathrm{pH}$ was adjusted with $\mathrm{HCl}$ or $\mathrm{NaOH}$ and checked by a glass-electrode $\mathrm{pH}$ meter $( \pm 0.05)$. Buffer $\mathrm{pH} 7.4$ : $\mathrm{Na}_{2} \mathrm{HPO}_{4}(0.595 \mathrm{~g}, 0.096 \mathrm{M})$ and $\mathrm{NaH}_{2} \mathrm{PO}_{4} \cdot 2 \mathrm{H}_{2} \mathrm{O}(0.125 \mathrm{~g}, 0.016 \mathrm{M})$ were dissolved in water $(50 \mathrm{~mL})$. Traces of transition metal ions were removed by treatment with Chelex ${ }^{\circledR} 100-200$ mesh particle size $(5 \mathrm{~g})$ for every $100 \mathrm{~mL}$ of sample, stirring gently for eight hours, then filtering the sample from the resin. Buffer solutions were mixed with the desired amount of THF (typically 3:1 by volume).

\subsection{Preparation of Ascorbic Acid Modified Halloysite $\left(H N T / A H_{2}\right)$}

A dispersion of HNTs (500 $\mathrm{mg}$, dry powder) in methanol $(10 \mathrm{~mL})$ was treated with ultrasound for $10 \mathrm{~min}$ to separate the tubes, after that $15 \mathrm{~mL}$ of ascorbic acid solution $0.19 \mathrm{M}$ in methanol was added. The suspension was evacuated for $10 \mathrm{~min}$ to remove air from within the tubes, and then was cycled back to atmospheric pressure. This process was repeated three times in order to increase the loading efficiency. The obtained dispersions were magnetically stirred overnight at room temperature under Argon. The solid was separated by centrifugation, washed with methanol to remove any organic material adsorbed in the outer HNT surface (without applying vacuum), and dried under high vacuum for $5 \mathrm{~h}$. The loading was repeated, in the same way, other two times by using the previously loaded HNTs and $15 \mathrm{~mL}$ of a freshly prepared solution of ascorbic acid $0.19 \mathrm{M}$ in methanol. The dried solid of ascorbic acid modified halloysite $\left(\mathrm{HNT} / \mathrm{AH}_{2}\right)$ was investigated by means of TGA analysis to estimate the antioxidant loading into the HNT lumen.

\subsection{Preparation of Ascorbic Acid Homogeneous Mixtures (M-x:AH $+H N T)$}

Homogeneous mixtures ascorbic acid/halloysite $\left(\mathrm{M}-\mathrm{x}: \mathrm{AH}_{2}+\mathrm{HNT}\right)$ were obtained by mixing a weighted amount of $\mathrm{AH}_{2}$ and HNTs in a mortar and pestle. Two M-x:AH $\mathrm{H}_{2}+\mathrm{HNT}$ at $4.4 \mathrm{wt} \%$ (M-4.4: $\left.\mathrm{AH}_{2}+\mathrm{HNT}\right)$ and $1.1 \mathrm{wt} \%\left(\mathrm{M}-1.0: \mathrm{AH}_{2}+\mathrm{HNT}\right)$ were prepared.

\subsection{Thermogravimetric Analysis (TGA)}

TGA experiments were carried out using a TA Instruments SDT-Q600 (New Castle, Germany) instrument on 12-18 mg samples in alumina crucibles. Samples were first heated from room temperature (RT) to $130{ }^{\circ} \mathrm{C}$ under inert atmosphere (nitrogen flow rate $100 \mathrm{~mL} / \mathrm{min}$ ) at a heating rate of $40^{\circ} \mathrm{C} / \mathrm{min}$, and isothermally kept at $130^{\circ} \mathrm{C}$ for $40 \mathrm{~min}$. Then, after switching to oxidizing atmosphere (air flow rate $100 \mathrm{~mL} / \mathrm{min}$ ), a second heating from $130{ }^{\circ} \mathrm{C}$ to $800{ }^{\circ} \mathrm{C}$ at a heating rate of $10{ }^{\circ} \mathrm{C} / \mathrm{min}$ was carried out. The TGA of ascorbic acid sample was carried out under an oxidizing atmosphere with a single run from RT to $600{ }^{\circ} \mathrm{C}$ at a heating rate of $10^{\circ} \mathrm{C} / \mathrm{min}$. Evaluation of the actual AA content in the samples was carried out according to Equation (1):

$$
\mathrm{AA} \%_{\mathrm{wt}}=\frac{\left(\mathrm{WL}_{130-800}-\mathrm{WL}_{H N T 130-800}\right)}{\left(\mathrm{SW}-\mathrm{WL}_{25-130}\right)} \times 100
$$


where $\mathrm{WL}_{130-800}$ is the weight loss of the AA containing samples in the second heating step from 130 to $800{ }^{\circ} \mathrm{C}$ after moisture removal, WL HNT 130-800 is the weight loss of the pristine reference HNT sample in the second heating step from 130 to $800{ }^{\circ} \mathrm{C}$ after moisture removal, SW is the starting weight of the sample, and $\mathrm{WL}_{25-130}$ is the moisture content evaluated during the first heating and isotherm step.

\subsection{Dynamic Light Scattering}

The hydrodynamic radii of dispersed particles were determined by dynamic light scattering (DLS) using a Malvern Zetasizer Nano ZS equipped with a $173^{\circ}$ backscatter detector and a He-Ne laser $(633 \mathrm{~nm})$. The ACN or aqueous solutions $(0.5 \mathrm{mg} / \mathrm{mL})$ were placed into poly(styrene) cuvettes with four optical faces and $1 \mathrm{~cm}$ optical path. The solutions were prepared and filtered $(0.45 \mu \mathrm{m}$ filter $)$ before the analysis. The field-time autocorrelation functions were analyzed by the inverse Laplace transform (ILT), which provides the decay rates $(\Gamma)$ of the diffusive modes. For the translational motion, the collective diffusion coefficient at a given concentration is $D_{t}=\Gamma / q^{2}$ where $q$ is the scattering vector given by $4\left(\pi n \lambda^{-1} \sin (\theta / 2)\right.$ being $n$ the acetonitrile refractive index, $\lambda$ the wavelength $(632.8 \mathrm{~nm})$ and $\theta$ the scattering angle $\left(173^{\circ}\right)$. The hydrodynamic diameter $\left(\mathrm{D}_{\mathrm{h}}\right)$ was calculated by means of Stokes-Einstein relation.

\subsection{UV-Vis Spectroscopy}

UV-VIS spectra were recorded in a Jasco V550 double-beam spectrometer (Lecco, Italy) versus the corresponding solvent. All spectra were recorded at room temperature with bandwidth of $1 \mathrm{~nm}$. The solutions were placed in standard $3.5 \mathrm{~mL}$ quartz cuvettes with path length of $10 \mathrm{~mm}$.

\subsection{Release of $\mathrm{AH}_{2}$ from $\mathrm{HNT} / \mathrm{AH}_{2}$}

Sample $\mathrm{HNT} / \mathrm{AH}_{2}$ was dispersed in $10 \mathrm{~mL}$ of acetonitrile or in $3 \mathrm{~mL}$ of aqueous buffer $(\mathrm{pH}=7.4)$, sonicated $1 \mathrm{~min}$, stirred $24 \mathrm{~min}$ and centrifuged $5 \mathrm{~min}$ to minimize light scattering by HNT. The calibration lines were obtained adding different amount (50 to $300 \mu \mathrm{L}$ ) of ascorbic acid $1.42 \mathrm{mM}$ to $3 \mathrm{~mL}$ of acetonitrile or ascorbic acid $1.65 \mathrm{mM}$ to $3 \mathrm{~mL}$ of water buffer $\mathrm{pH}=7.4$.

\subsection{Stability Studies of $\mathrm{AH}_{2}$}

Ascorbic acid ( $3 \mathrm{mg}$ ) was dissolved in $10 \mathrm{~mL}$ of solvent (acetonitrile, methanol or aqueous buffer $\mathrm{pH}=7.4$ ). $200 \mu \mathrm{L}$ were diluted in $3 \mathrm{~mL}$ of the same solvent to obtain a final concentration $1.1 \times 10^{-4} \mathrm{M}$. Degradation was monitored spectrophotometrically at: $\lambda=238 \mathrm{~nm}$ for acetonitrile, $\lambda=246 \mathrm{~nm}$ for methanol and $\lambda=265 \mathrm{~nm}$ for aqueous buffer.

\subsection{Determination of DPPH• Scavenging}

The reaction mixtures were prepared by adding to a solution $143 \mu \mathrm{M}$ of DPPH• radical in acetonitrile $(3.5 \mathrm{~mL}), 50 \mu \mathrm{L}$ of ascorbic acid $4 \mathrm{mM}$, or $1 \mathrm{mg}$ of $\mathrm{HNT} / \mathrm{AH}_{2}$. The solution was sonicated for $20 \mathrm{~min}$ and centrifuged for $10 \mathrm{~min}$ to minimize light scattering by HNT. Absorption of DPPH• was determined by recording the spectra in sequence until the absorbance was unchanged $(8 \mathrm{~h})$ and against a blank solution that contained only acetonitrile $\left(\lambda_{\max }=517 \mathrm{~nm}, \varepsilon=11,000 \pm 50\right)$ [37].

\subsection{Autoxidation Experiments}

The kinetics of reaction with alkylperoxyl radicals was studied by autoxidation experiments in a differential oxygen-uptake apparatus based on a Validyne DP 15 pressure transducer built in our laboratory and described previously [39-42]. Autoxidation experiments consisted in monitoring the inhibition of oxygen consumption during the autoxidation of cumene $(1.8 \mathrm{M})$ in acetonitrile or THF (3.1 M) in aqueous phosphate buffer. In a typical experiment, a thermal initiator was added to an air-saturated mixture of the oxidizable substrate and the solvent, i.e., AIBN (0.05 M) was used to start the autoxidation of cumene/acetonitrile 1:3 $(v / v)$, and AAPH $(25 \mathrm{mM})$ was the initiator for 
THF/water 1:3 $(v / v)$ containing the buffer $(0.1 \mathrm{M})$. Upon connection to the oxygen-uptake apparatus, the reacting mixture (sample) was equilibrated with an identical reference solution containing an excess of 2,2,5,7,8-pentamethyl-6-chromanol (to cause complete inhibition of the reference). When a constant rate $\mathrm{O}_{2}$ consumption was reached, $10-50 \mu \mathrm{L}$ of a concentrated solution of the test antioxidant $\left(\mathrm{AH}_{2}\right.$ or $\left.\mathrm{HNT} / \mathrm{AH}_{2}\right)$ in the appropriate solvent (acetonitrile or water) was injected into the sample flask and oxygen consumption in the sample was measured. From the slope of oxygen consumption in the absence of antioxidant $\left.\left(-\mathrm{d}\left[\mathrm{O}_{2}\right] / \mathrm{d} t\right)_{0}=R_{\mathrm{ox} 0}\right)$ and during the inhibited period $\left.\left(-\mathrm{d}\left[\mathrm{O}_{2}\right] / \mathrm{d} t\right)=R_{\mathrm{ox}}\right)$, $k_{\text {inh }}$ values were obtained by using Equation (2) while the $n$ coefficients were determined from the length of the inhibited period $(\tau)$ by using Equation (3), from the known rate of radical production by AIBN or AAPH (initiation rate, $R_{i}$ ) [22]:

$$
\begin{gathered}
\frac{R_{o x 0}}{R_{o x}}-\frac{R_{o x}}{R_{o x 0}}=\frac{n k_{i n h}[A H]_{0}}{\sqrt{2 k_{t} R_{i}}}, \\
n=\frac{R_{i} \tau}{[\text { antioxidant }]}
\end{gathered}
$$

The $2 k_{t}$ values of cumene, styrene, and THF at $303 \mathrm{~K}$ are $4.6 \times 10^{4}, 4.2 \times 10^{7}$, and $6.6 \times 10^{7} \mathrm{M}^{-1} \mathrm{~s}^{-1}$, respectively. The value of $R_{i}$ was determined under each experimental condition by using PMHC (2,2,5,7,8-pentamethyl-6-chromanol) or Trolox (( \pm )-6-hydroxy-2,5,7,8tetramethylchromane-2-carboxylic acid) with $n=2$ as a reference antioxidant: system = acetonitrile/cumene, $R_{\mathrm{i}}=5.2 \times 10^{-9} \mathrm{M} \mathrm{s}^{-1}$; system = acetonitrile/styrene, $R_{\mathrm{i}}=6.7 \times 10^{-9} \mathrm{M} \mathrm{s}^{-1}$; system $=$ buffer $\mathrm{pH} 7.4 / \mathrm{THF}, R_{\mathrm{i}}=7.3 \times 10^{-9} \mathrm{M} \mathrm{s}^{-1}$.

\section{Results and Discussion}

\subsection{Preparation and Characterization of $\mathrm{HNT} / \mathrm{AH}_{2}$}

Selective loading of ascorbic acid into HNT lumen was achieved by exploiting the different structure of the inner and outer surfaces of the nanotube with the basic inner lumen having much higher affinity for ascorbic acid ( $\mathrm{pKa}=4.2)$ than the moderately acidic outer silica surface [27]. Loading was carried out by repeated vacuum cycling of a HNT suspension in a solution of ascorbic acid in methanol, under argon atmosphere, followed by isolation of solid $\mathrm{HNT} / \mathrm{AH}_{2}$ by centrifugation, washing of the outer surface with methanol (no vacuum applied) to remove $\mathrm{AH}_{2}$ adsorbed on the outer HNT surface, and drying under vacuum (Scheme 1). For optimal loading the whole cycle was repeated three times (additional cycles can be used to further increase loading). The composite solid $\mathrm{HNT} / \mathrm{AH}_{2}$ was characterized by thermogravimetric analysis (TGA) with the aim to assess the real content of the antioxidant within the modified halloysite, as reported in the recent literature for similar products $[33,43-45]$. HNT/ $\mathrm{AH}_{2}$ was analyzed by TGA, together with the unmodified sample (HNT) and the pristine $\mathrm{AH}_{2}$, as a reference. The TGA thermograms of pristine $\mathrm{AH}_{2}$ display a complex multi-step degradation pattern that, however, takes place only after reaching $190{ }^{\circ} \mathrm{C}$ (Figure $1 \mathrm{~A}$ ). Since halloysite tends to adsorb water, whose actual amount depends on the storage condition, each sample was preliminarily heated under nitrogen atmosphere from room temperature up to $130{ }^{\circ} \mathrm{C}$ and held at this temperature for $40 \mathrm{~min}$. In these conditions, the adsorbed water is completely removed, thus allowing the direct comparison of any further weight loss in the samples (Figure 1B).

In these conditions, further undesired oxidation of the organic compounds can be safely ruled out, as demonstrated by the thermogravimetric curve of the pristine $\mathrm{AH}_{2}$ (Figure $1 \mathrm{~A}$ ) that does not show any weight loss at temperatures below $190{ }^{\circ} \mathrm{C}$. Then, upon switching the atmosphere to air and raising the temperature up to $800{ }^{\circ} \mathrm{C}$ the degradation of all the organic and structural components occurs. As shown in Figure 1B, the HNT thermogram displays two weight losses: the first one around $100{ }^{\circ} \mathrm{C}$ (1-2\%wt, 0-10 $\mathrm{min}$ ) ascribed to the evaporation of water absorbed on the surface of the sample and the second one (13.8\%wt), at about $500{ }^{\circ} \mathrm{C}(70-90 \mathrm{~min})$, related to the loss of constitutional water [44,45]. The HNT $/ \mathrm{AH}_{2}$ shows, besides the previously discussed weight losses, an additional degradation step, 
located in the $180-400{ }^{\circ} \mathrm{C}$ temperature range (40-70 min, partially overlapping the subsequent weight loss), which covers not only the structural water release, but also the ascorbic acid degradation, in agreement with the previously discussed TGA profile of pristine $\mathrm{AH}_{2}$ (Figure 1A).

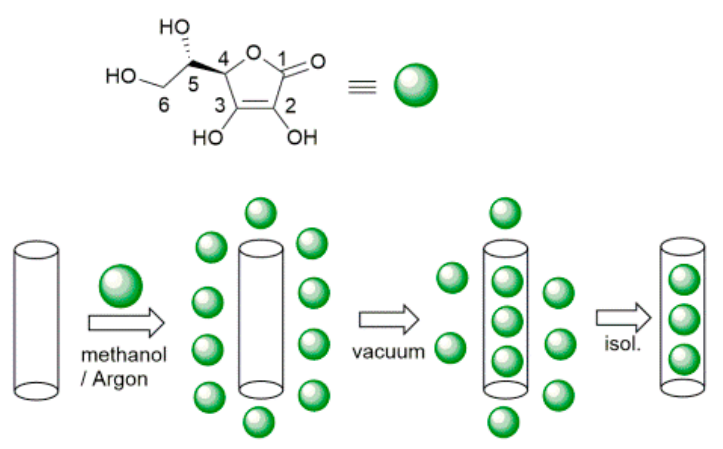

Scheme 1. Preparation of ascorbic acid loaded halloysite nanotubes $\left(\mathrm{HNT} / \mathrm{AH}_{2}\right)$.
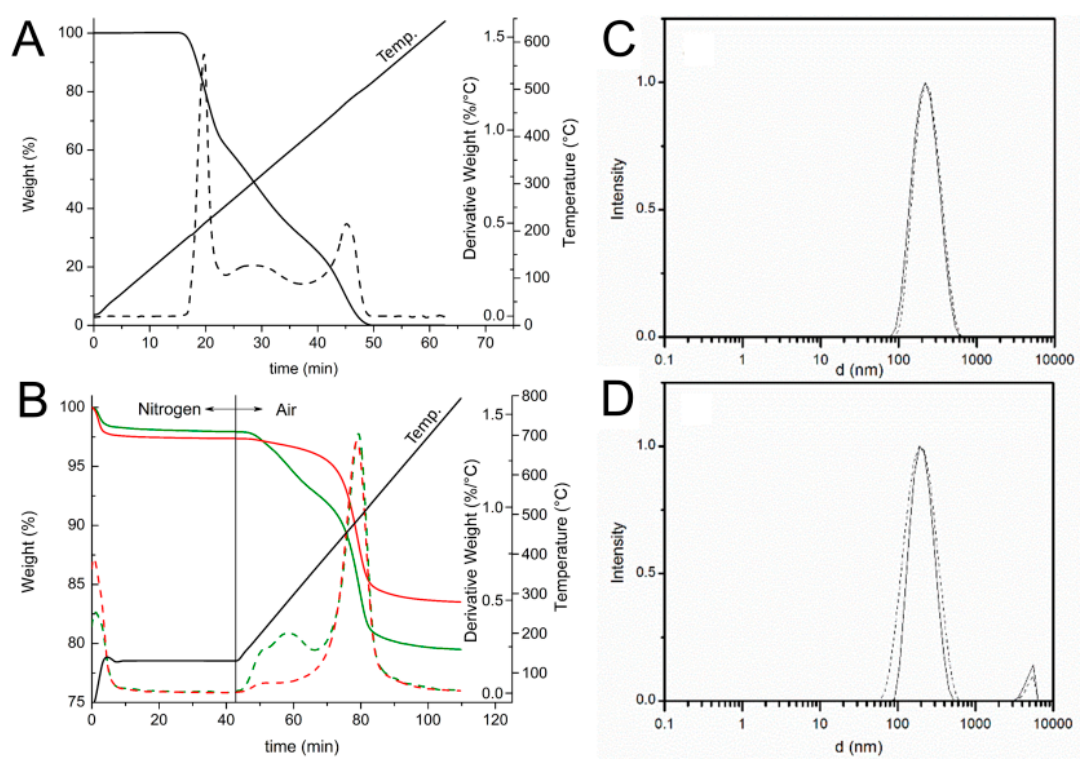

Figure 1. (A,B) TGA (solid line) and derivative DTG (broken line) thermograms of: (A) ascorbic acid $\left(\mathrm{AH}_{2}\right)$ under air atmosphere at heating rate of $10^{\circ} \mathrm{C} / \mathrm{min}$; and $(\mathbf{B}) \mathrm{HNT}(-)$ and $\mathrm{HNT} / \mathrm{AH}_{2}$ (—). The temperature profile applied during the measurement is reported. (C,D) DLS intensity distribution ofHNT (solid line) and $\mathrm{HNT} / \mathrm{AH}_{2}$ (broken line) (C) in acetonitrile; and (D) in water solution $(0.5 \mathrm{mg} / \mathrm{mL})$.

In order to validate the applied method and verify the accuracy of the developed TGA approach, two homogeneous physical mixtures of known composition (1.0 $\mathrm{wt} \%$ and $4.4 \mathrm{wt} \%$ mixtures of ascorbic acid in halloysite: $\mathrm{M}-1.0: \mathrm{AH}_{2}+\mathrm{NHT}$ and $\left.\mathrm{M}-4.4: \mathrm{AH}_{2}+\mathrm{NHT}\right)$ were also analyzed in the same conditions. Results reported in Figure S1 (see Supplementary Materials) and Table 1 display that the preliminary water removal step does not affect the overall measurements and the applied method is sensitive enough to discriminate the $\mathrm{AH}_{2}$ content down to at least $1 \% \mathrm{wt}$.

Thus, by comparing the thermograms of $\mathrm{HNT} / \mathrm{AH}_{2}$ with that one of the pristine $\mathrm{HNT}$, once the absorbed water contribution has been removed, it is possible to evaluate the antioxidant fraction inside the inorganic frame, which results $4.6 \pm 0.1 \mathrm{wt} \%$ in $\mathrm{HNT} / \mathrm{AH}_{2}$. 
Table 1. TGA data of pristine (HNT) and modified $\left(\mathrm{HNT} / \mathrm{AH}_{2}\right)$ halloysite, along with plain ascorbic acid $\left(\mathrm{AH}_{2}\right)$ and reference $\mathrm{AH}_{2}+\mathrm{HNT}$ physical mixtures.

\begin{tabular}{|c|c|c|c|}
\hline Samples & $\begin{array}{l}\text { Moisture Content } \\
\qquad(w t \%)^{1}\end{array}$ & $\begin{array}{l}\text { Weight Loss from } 130 \text { to } \\
800{ }^{\circ} \mathrm{C}(\mathrm{wt} \%)^{2}\end{array}$ & $\begin{array}{c}\text { Estimated } \mathrm{AH}_{2} \\
\text { Fraction }(\%)^{3}\end{array}$ \\
\hline HNT & $2.60 \pm 0.05$ & $13.80 \pm 0.05$ & 0 \\
\hline $\mathrm{HNT} / \mathrm{AH}_{2}$ & $2.10 \pm 0.05$ & $18.40 \pm 0.05$ & $4.6 \pm 0.1$ \\
\hline $\mathrm{M}-1.0: \mathrm{AH}_{2}+\mathrm{HNT}$ & $2.00 \pm 0.05$ & $15.00 \pm 0.05$ & $1.2 \pm 0.1$ \\
\hline $\mathrm{M}-4.4: \mathrm{AH}_{2}+\mathrm{HNT}$ & $2.20 \pm 0.05$ & $18.20 \pm 0.05$ & $4.4 \pm 0.1$ \\
\hline
\end{tabular}

${ }^{1}$ Weight loss determined by TGA in nitrogen atmosphere (heating rate $10^{\circ} \mathrm{C} / \mathrm{min}$ ) from RT to $130{ }^{\circ} \mathrm{C}$ and after an isotherm at $130{ }^{\circ} \mathrm{C}$ for $40 \mathrm{~min} .{ }^{2}$ Weight loss determined by TGA in air (heating rate $10^{\circ} \mathrm{C} / \mathrm{min}$ ) from 130 to $800^{\circ} \mathrm{C}$, ${ }^{3}$ Weight loss determined by TGA subtracting the HNT weight change in the range $130-800{ }^{\circ} \mathrm{C}(13.8 \%)$ from the AA modified HNT weight change in the range $130-800^{\circ} \mathrm{C}$.

The dimension of $\mathrm{HNT} / \mathrm{AH}_{2}$ and the effect of the addition of ascorbic acid to the nanotubes was assessed by dynamic light scattering (DLS) studies in water and ACN solutions. As reported in Figure $1 \mathrm{C}, \mathrm{D}$, both pristine $\mathrm{HNT}$ and composite $\mathrm{HNT} / \mathrm{AH}_{2}$ display a uni-modal distribution of particles size, centered around $230 \mathrm{~nm}$, which is not substantially affected by the solvent. The measured particle dimension well compares with literature data concerning similar structures thus confirming that no aggregation occurs in both the analyzed samples even upon introduction of $\mathrm{AH}_{2}$ in the nanotubes.

This is at variance with previous work with HNT, in which functionalization of the external surface (as opposed to loading in the inner lumen) caused clustering of the nanotubes held together by interaction of the organic material on the outer surface, resulting and the appearance of a second broad-sized population with higher hydro-dynamic diameter [33].

The morphology of $\mathrm{HNT} / \mathrm{AH}_{2}$ was imaged by TEM (Figure 2). It clearly appears that the tubular shape of the halloysite is maintained after $\mathrm{AH}_{2}$ loading, and no actual external modification is visible. The HNT diameter and length are in line with the typical values (see Sections 1 and 2.1).

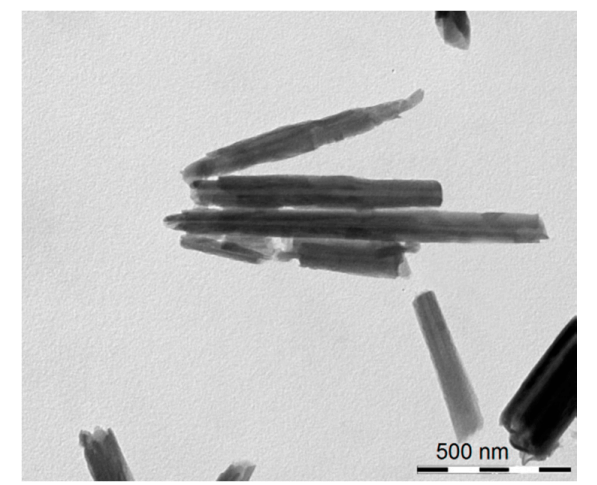

(a)

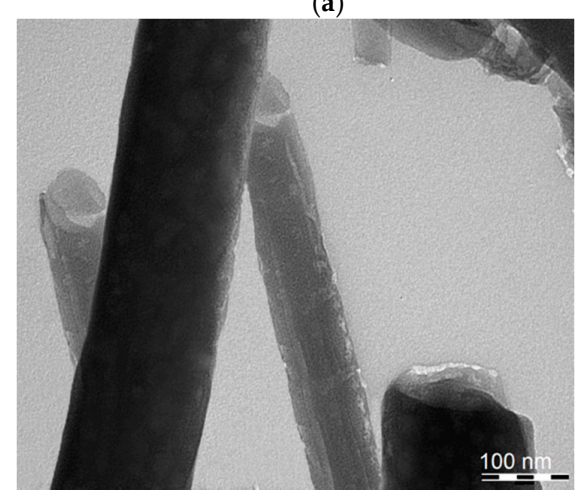

(c)

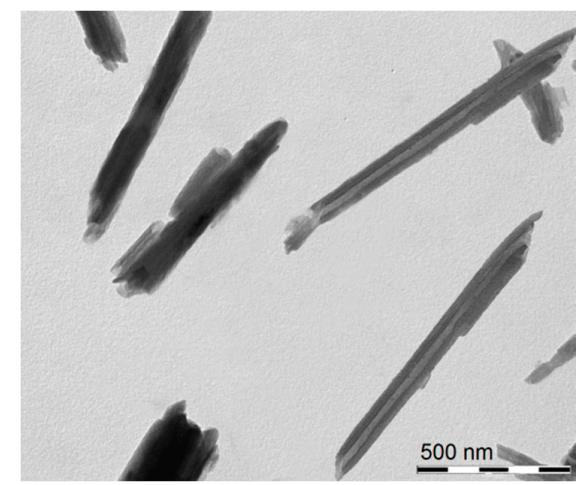

(b)

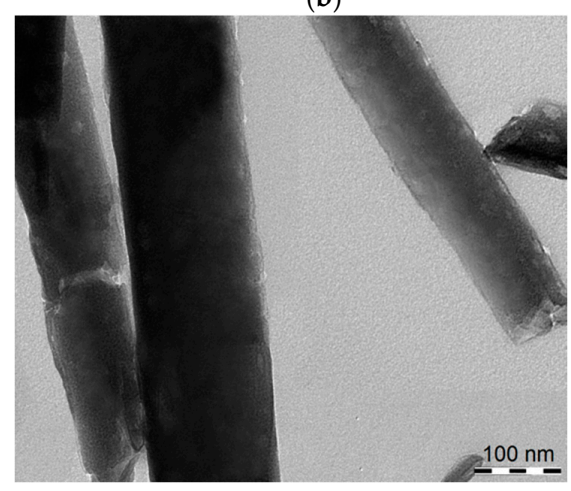

(d)

Figure 2. Transmission electronic microscopy (TEM) images of (a,c) pristine HNT; $(\mathbf{b}, \mathbf{d})$ of $\mathrm{HNT} / \mathrm{AH}_{2}$ showing the nanotubular structure. Scale bars: (a,b) $500 \mathrm{~nm}$; and (c,d) $100 \mathrm{~nm}$. 


\subsection{Release of Ascorbic Acid from $\mathrm{HNT} / \mathrm{AH}_{2}$}

The release of ascorbic acid from the HNT cavity was investigated both in water buffered at $\mathrm{pH} 7.4$ and in acetonitrile chosen as the reference organic solvent, also used in subsequent measurements of antioxidant activity. Samples of $\mathrm{HNT} / \mathrm{AH}_{2}$ were dispersed in the investigation solvent, briefly sonicated and the amount of released $\mathrm{AH}_{2}$ after $30 \mathrm{~min}$ at $298 \mathrm{~K}$ was evaluated by UV-Vis spectrophotometry upon calibration with pristine $\mathrm{AH}_{2}$. Results (see Supplementary Materials, Tables S1 and S2) indicate that only about half of the loaded $\mathrm{AH}_{2}$ is effectively released in $30 \mathrm{~min}$, which is the typical time-lapse observed in inhibited autoxidation studies to assess antioxidant activity. On extending the analysis to eight hours, additional release was observed, however, the instability of ascorbic acid in the receptor solution prevented accurate quantitation. The more rapid release of a portion of ascorbic acid in solution, followed by a slower release on the remaining antioxidant, can be rationalized on the basis of previous work on quercetin-loaded HNT [33]. Considering the specific surface area [27] and nanotube size of halloysite (see Section 2.1) and that its cavity accounts for about $10 \%$ of its volume [46], and considering ascorbic acid molecular surface, it can be estimated that a monolayer of ascorbic acid adsorbed in the inner lumen would account for about $2 \mathrm{wt} \%$, of the whole composite material, in line with previous calculations for the load of other molecules $[33,46]$. This estimate is close to $50 \%$ of the loaded ascorbic acid. Over such a monolayer, which is strongly bound to the inner surface, additional layers of more loosely-bound organic material stratify in the inner lumen, being more rapidly released upon interaction with the solvent [33], which accounts for the observed rapidly released $50 \%$ of load.

As anticipated instability of ascorbic acid in solution prevented accurate analysis of the full kinetics of release. To further investigate this aspect, the stability of pristine $\mathrm{AH}_{2}$ was monitored both in aqueous and organic solution.

\subsection{Stability of Ascorbic Acid $\left(\mathrm{AH}_{2}\right)$ in Solution}

Despite the instability of ascorbic acid in solution has been known for almost a century, the kinetics and mechanism of degradation, along with the influence of experimental conditions are still debated and controversial. Product studies indicate that, under aerobic conditions in aqueous environment, degradation steps from formal two-electrons oxidation by molecular oxygen to yield dehydroascorbic acid (A) (Scheme 2), which hydrolyzes to diketogluconic acid (DKA) that further transforms in a variety of products [47], including furfuroic acid, 3-hydroxy-2-pyrone [14,47,48], and hydroxymethylfurfural [17]. Anaerobic (hydrolytic) degradation to furfural has also been observed [14]. Products' distribution is reported to depend on $\mathrm{pH}$ [47]. Focusing on initial oxidation to dehydroascorbic acid (A), the process has been indicated to occur by a cascade of one-electron processes (an autoxidation chain-reaction) stepping either from $\mathrm{AH}_{2}$ or from the electron richer ascorbate mono-anion $\left(\mathrm{AH}^{-}\right)$[47], which would be prevalent at close to neutral $\mathrm{pH}$ (ascorbic acid has $\left.\mathrm{p} K_{\mathrm{a}}=4.2\right)$ (Scheme 2). The chain reaction is mediated by the superoxide radical $\mathrm{HOO} \bullet / \mathrm{O}_{2}{ }^{-} \bullet$ $\left(\mathrm{p} K_{\mathrm{a}}=4.2\right)$ [49], as summarized in Scheme 2, and is catalyzed by traces of transition metal ions [50,51].

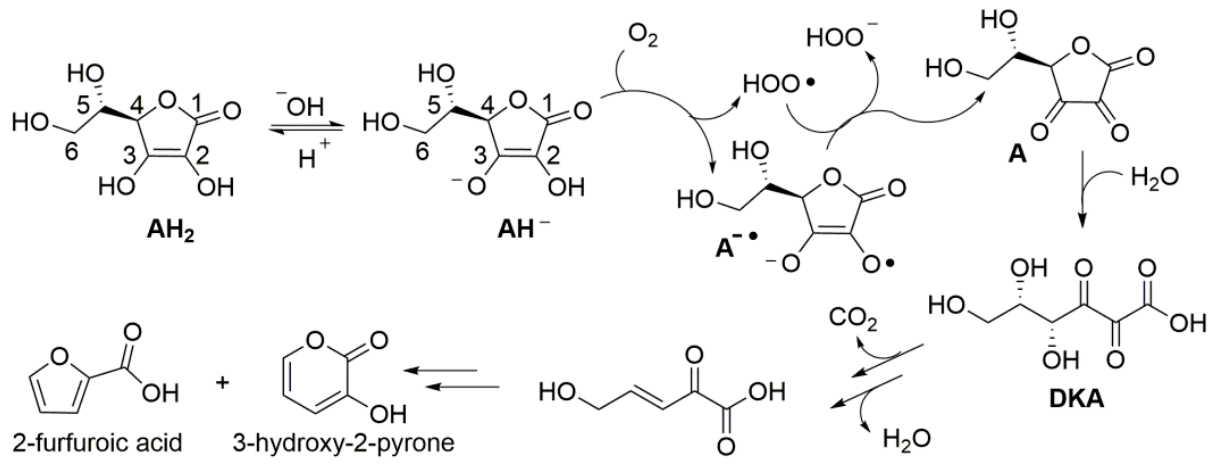

Scheme 2. Aerobic degradation of ascorbic acid $\left(\mathrm{AH}_{2}\right)$ in aqueous solution. 
While some authors suggest that traces of metals are necessary to sustain the process [51], others indicate that oxidation can only occur from the mono-anion $\left(\mathrm{AH}^{-}\right)$[49]. Concerning the kinetics, while it is generally recognized as being first-order with respect of oxygen concentration [50], with respect of $\mathrm{AH}_{2}$ concentration it has been reported by some authors to be zero-order [16,50], by others to be first-order [17,49,51], yet by others second-order [52]. Similarly, Cabelli and Blelskl indicate a dependence on $\mathrm{pH}$ [49], while Wilson et al., reported that neither the mechanism nor the observed pseudo-first-order rate constant change significantly on changing the $\mathrm{pH}$ value [50]. This uncertainty is not totally surprising considering the complexity of the process; however, it does not aid the on-setting of strategies for the stabilization of ascorbic acid. Additionally, little is known on the stability of $\mathrm{AH}_{2}$ in organic solution.

Although a detailed investigation is this regard was outside the scope of this study, in order to set our subsequent measurements of antioxidant activity on solid ground, we comparatively monitored the kinetics of degradation of $\mathrm{AH}_{2}$ under our experimental settings, i.e., in air-saturated solution at $298 \mathrm{~K}$, in buffered ( $\mathrm{pH}=7.4$ ) water, in methanol, and in acetonitrile. As summarized in Figure 3, significant degradation of $\mathrm{AH}_{2}$ was recorded in all the investigated solvents with methanol largely paralleling buffered water, while it was slower in acetonitrile. During the first four hours of monitoring, when about $80 \%$ of $\mathrm{AH}_{2}$ had disappeared in water or methanol (about $20 \%$ in acetonitrile), the process was found to follow pseudo-first-order kinetics (concentration of oxygen was kept constant), being of apparent first-order with respect to the $\mathrm{AH}_{2}$ concentration (see Figure S6). Apparent pseudo-first-order rate constants $k_{1 \mathrm{st}}$ at $298 \mathrm{~K}$ were $1.18 \times 10^{-4} \mathrm{~s}^{-1}, 1.20 \times 10^{-4} \mathrm{~s}^{-1}$, and $3.93 \times 10^{-5} \mathrm{~s}^{-1}$, respectively, in air saturated water $(\mathrm{pH}=7.4)$, methanol, and acetonitrile (see Supplementary Materials, Figures S4-S6). Non-zero-order dependence of the rate of degradation on $\mathrm{AH}_{2}$ concentration is important to the efficacy of our approach, as it relies on the slow release of $\mathrm{AH}_{2}$ in solution during the autoxidation, which is expected to slow down degradation by keeping a reduced concentration of $\mathrm{AH}_{2}$ in solution at any time.

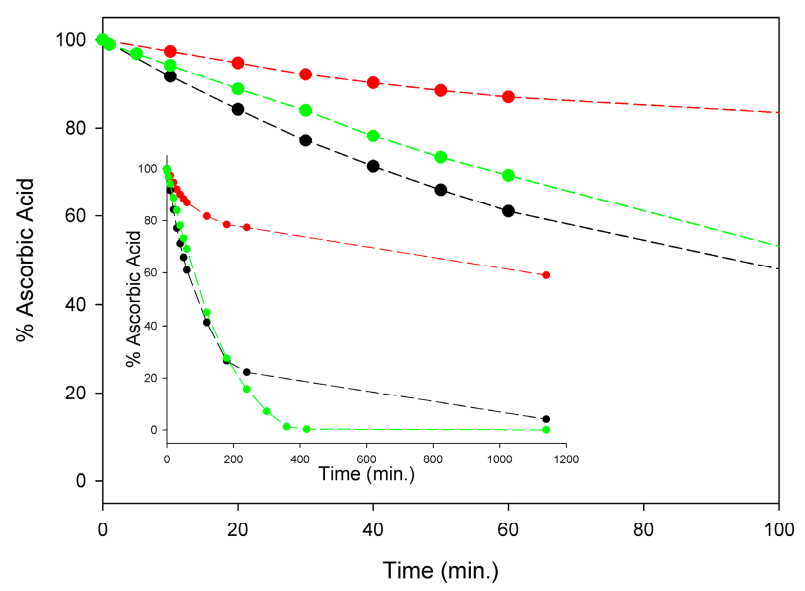

Figure 3. Stability of $100 \mu \mathrm{M}$ ascorbic acid $\left(\mathrm{AH}_{2}\right)$ in acetonitrile (red), water buffer $\mathrm{pH}=7.4$ (green) and methanol (black) at $298 \mathrm{~K}$, in the presence of atmospheric oxygen. Insert shows the full time-course of $\mathrm{AH}_{2}$ decay expressed as remaining \% of the starting concentration, while main graph represents the scale expansion for the first 100 min (kinetic analysis is shown in Figures S4-S6).

\subsection{Radical Trapping and Antioxidant Activity of $\mathrm{HNT} / \mathrm{AH}_{2}$}

\subsubsection{DPPH• Radical Trapping}

In order to assess the radical reactivity or $\mathrm{HNT} / \mathrm{AH}_{2}$ we monitored by spectrophotometry its reaction with persistent 2,2-diphenyl-1-pycryl-1-hydrazyl radical (DPPH•), which is often used as radical model [33,35]. Under matched experimental settings, in acetonitrile, at $298 \mathrm{~K}$ both $\mathrm{HNT} / \mathrm{AH}_{2}$ and pristine $\mathrm{AH}_{2}$ rapidly reduced $\mathrm{DPPH} \bullet$ to the corresponding hydrazine $\mathrm{DPPH}_{2}$. Pristine $\mathrm{AH}_{2}$ 
quenched DPPH• with a stoichiometric factor (the number of radicals trapped by one molecule of antioxidant) $n=1.9$, in good agreement with the theoretical value of 2 (see Scheme S1) [35]. Therefore, by assuming identical stoichiometry of the reaction, we could determine the reducing equivalents of ascorbic acid released by HNT/ $\mathrm{AH}_{2}$. Results (see Figure S7 in Supplementary Materials) indicated that $\mathrm{HNT} / \mathrm{AH}_{2}$ releases $2.4 \pm 0.1 \mathrm{wt} \% \mathrm{AH}_{2}$ in the reactive reduced form, which is coincident, within experimental error, to the total value of $\mathrm{AH}_{2}$ released in solution (see Supplementary Materials, Tables $\mathrm{S} 1$ and S2). This implies that $\mathrm{AH}_{2}$ released is entirely in the reduced form and supports the idea that $\mathrm{HNT} / \mathrm{AH}_{2}$ would act as an effective antioxidant material.

\subsubsection{Antioxidant Activity (ROO• Radical Trapping)}

Antioxidant activity of $\mathrm{HNT} / \mathrm{AH}_{2}$ was evaluated in comparison with native $\mathrm{AH}_{2}$ (Figure 4), by measuring the rate constant $\left(k_{\text {inh }}\right)$ for the reaction with alkylperoxyl radicals (ROO•) during the controlled inhibited autoxidation of a standard substrate (Equations (4)-(9)) [11,13]. This is the most valuable method to gain quantitative information on antioxidant activity, as peroxyl radicals are responsible for the propagation step of peroxidation processes (Equation (6)) in most natural and man-made materials $[35,36]$. Studies were performed both in buffered $(\mathrm{pH}=7.4)$ water solution (Figure 4B,D), using tetrahydrofuran as a standard substrate [18], and in acetonitrile, as a reference organic solvent, using cumene as the oxidizable substrate (Figure $4 \mathrm{~A}, \mathrm{C})$ [22].

$$
\begin{aligned}
& \text { Initiator } \stackrel{R_{i}}{\rightarrow} R \bullet \text {, } \\
& \mathrm{R} \bullet+\mathrm{O}_{2} \stackrel{\text { diffusion }}{\longrightarrow} \mathrm{ROO} \bullet \\
& \mathrm{ROO} \bullet+\mathrm{RH} \stackrel{k_{p}}{\longrightarrow} \mathrm{R} \bullet+\mathrm{ROOH}, \\
& 2 R O O \bullet \stackrel{k_{t}}{\longrightarrow} \text { non radical products, } \\
& \mathrm{ROO} \bullet+\mathrm{AH}_{2} \stackrel{k_{\text {inh }}}{\longrightarrow} \mathrm{ROOH}+\mathrm{AH} \bullet, \\
& \mathrm{ROO} \bullet+A H \bullet \stackrel{\text { diffusion }}{\longrightarrow} \mathrm{ROOH}+A, \\
& \mathrm{AH}_{2}+\mathrm{O}_{2} \rightarrow \mathrm{AH} \bullet+\mathrm{HOO} \bullet, \\
& \mathrm{AH} \bullet+\mathrm{O}_{2} \rightarrow \mathrm{A}+\mathrm{HOO} \bullet, \\
& \mathrm{AH}_{2}+\mathrm{HOO} \bullet \rightarrow \mathrm{AH} \bullet+\mathrm{HOOH}, \\
& \mathrm{AH} \bullet+\mathrm{HOO} \bullet \rightarrow A+\mathrm{HOOH}, \\
& \mathrm{HOO} \bullet+\mathrm{RH} \rightarrow \mathrm{HOOH}+\mathrm{R} \bullet \text {, }
\end{aligned}
$$

Autoxidations were performed at $303 \mathrm{~K}$ using, respectively, 2,2'-azobis(2-amidinopropane) dihydrochloride (AAPH) or 2,2'-azobisisobutyronitrile (AIBN) as the initiator in aqueous or organic solution, and were followed by monitoring the oxygen consumption in a differential oxygen-uptake apparatus [36]. In the presence of antioxidants, oxidation of the substrate and oxygen consumption are slowed down and a neat inhibition period might become visible (as observed in Figure 4), until the antioxidant is consumed. 

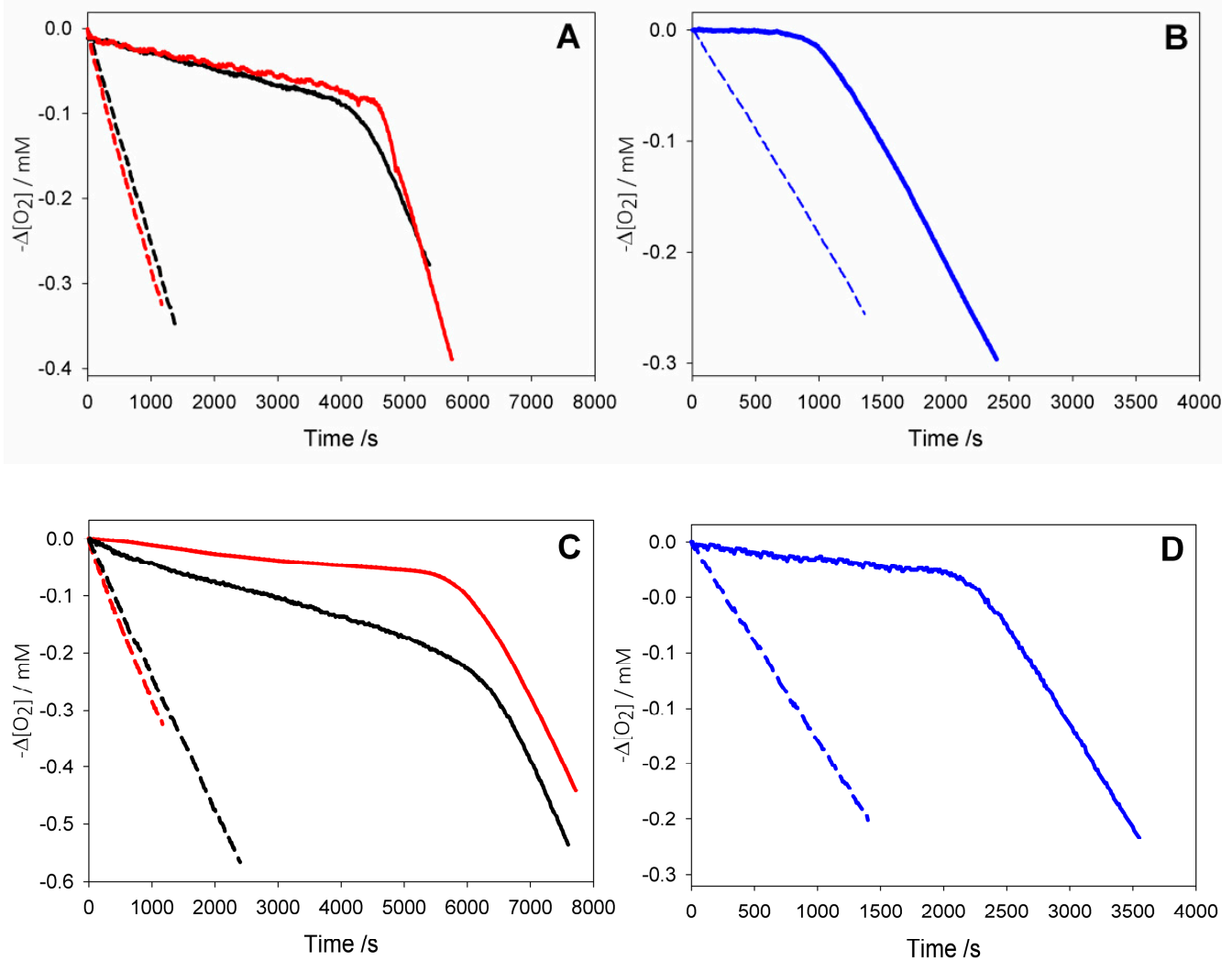

Figure 4. Oxygen consumption during the autoxidation of: (black) cumene (1.8 M) initiated by AIBN $(0.05 \mathrm{M})$ at $30^{\circ} \mathrm{C}$ in dry acetonitrile, or (red) with addition of $1 \%$ wt water $(\mathbf{A}, \mathbf{C})$, and (blue) during the autoxidation of THF (3.1 M) initiated by AAPH $(25 \mathrm{mM})$ in phosphate buffer $(0.1 \mathrm{M} \mathrm{pH}=7.4)$ at $30^{\circ} \mathrm{C}(\mathbf{B}, \mathbf{D})$ without inhibitors (dash line); or in the presence of $\mathrm{AH}_{2} 2.5 \times 10^{-5} \mathrm{M}$ (solid line, $\mathbf{A}$ ); or of $\mathrm{AH}_{2} 2.2 \times 10^{-5} \mathrm{M}$ (solid line, $\mathbf{B}$ ); or in the presence of $\mathrm{HNT} / \mathrm{AH}_{2} 0.18 \mathrm{mg} / \mathrm{mL}$ (corresponding to $\mathrm{AH}_{2} 2.5 \times 10^{-5} \mathrm{M}$, solid line, $\mathrm{C}$ ); or in the presence of $\mathrm{HNT} / \mathrm{AH}_{2} 0.16 \mathrm{mg} / \mathrm{mL}$ (corresponding to $\mathrm{AH}_{2}$ $2.2 \times 10^{-5} \mathrm{M}$, solid line, D).

Analysis of $\mathrm{O}_{2}$ uptake affords both the rate constant $k_{\text {inh }}$ and the stoichiometric factor $n$, respectively, from the slope and the length of the inhibition period in the plots, according to Equations (2) and (3). In acetonitrile, native ascorbic acid $\mathrm{AH}_{2}$ had fairly good antioxidant activity (Figure $4 \mathrm{~A}$ ) with measured $k_{\text {inh }}$ of about $3 \times 10^{4} \mathrm{M}^{-1} \mathrm{~s}^{-1}$ which remains unchanged within experimental error upon addition of $1 \%$ water (see Table 2). Interestingly, however, its stoichiometric factor $n$ varied with the concentration of the antioxidant: $\mathrm{AH}_{2}$ was able to trap two peroxyl radicals (Equations (8) and (9)) when it was used at very low concentration (lower than $1 \mu \mathrm{M}$ ); however, it progressively decreased to less than one peroxyl radical per molecule of $\mathrm{AH}_{2}$ when used at more realistic concentration of $25 \mu \mathrm{M}$ or higher, as shown in Figure 5A. This progressive loss of antioxidant efficiency can be attributed to the competing oxidation of both ascorbic acid and the ascorbyl radical by molecular oxygen, with the generation of superoxide radicals (Equations (10) and (11)) that deplete the antioxidants (Equations (12) and (13)) and initiate new oxidative chains (Equation (14)). Indeed, the reaction of $\mathrm{AH}_{2}$ with oxygen causes both unproductive depletion of the antioxidant and pro-oxidant behaviour that partially competes with the antioxidant function. The importance of side reactions (Equations (10)-(14)), as compared to antioxidant reactions (Equations (8) and (9)), increases with the concentration of $\mathrm{AH}_{2}$ in solution, as it would affect the steady-state concentration of alkyperoxyl radicals, explaining the progressive decline in the antioxidant activity. As expected, in buffered water solution ( $\mathrm{pH} 7.4$ ) the antioxidant activity of ascorbic acid was much higher (see Figure $4 \mathrm{~B}$ vs. Figure $4 \mathrm{~A}$ ), with $k_{\text {inh }}$ as large as $1.7 \times 10^{6} \mathrm{M}^{-1} \mathrm{~s}^{-1}$, in line with previous studies [18] and with the notation that ascorbic acid has been selected by nature primarily as a water-soluble antioxidant. 
Higher reactivity with peroxyl radicals is due to preliminary acidic dissociation to ascorbate (the prevailing species at $\mathrm{pH}$ 7.4) which is electron-richer and rapidly reacts with peroxyl radicals by proton-coupled-electron-transfer (Equations (15) and (16)) [18]. Unfortunately, conversion into ascorbate may also facilitate the competing reaction with dioxygen (Equation (17)):

$$
\begin{gathered}
\mathrm{AH}_{2}+\mathrm{OH}^{-} \rightarrow \mathrm{AH}^{-}+\mathrm{H}_{2} \mathrm{O}, \\
A H^{-}+\mathrm{ROO} \bullet \rightarrow A \bullet^{-}+\mathrm{ROOH}, \\
A H^{-}+\mathrm{O}_{2} \rightarrow A \bullet^{-}+\mathrm{HOO} \bullet,
\end{gathered}
$$

This is immediately evident upon comparing the length of the inhibited period in Figure 4B (in water) with those in Figure 4A (in acetonitrile) recorded at similar concentration of $\mathrm{AH}_{2}$. Indeed, in water the recorded loss of antioxidant efficiency upon increasing the concentration of $\mathrm{AH}_{2}$ was even more dramatic than in organic solution (Figure $5 \mathrm{~B}$ ) and, on increasing $\left[\mathrm{AH}_{2}\right]$ from $1 \mu \mathrm{M}$ to $81 \mu \mathrm{M}, n$-value dropped from about 2 to less than 0.1, confirming previous studies under similar experimental settings [19], and meaning almost complete abolition of the antioxidant role.

As expected, under similar settings either in acetonitrile or in buffered water, pristine HNT did not display any antioxidant behaviour; however, $\mathrm{HNT} / \mathrm{AH}_{2}$ had excellent antioxidant activity (Figure 4C,D). Both in acetonitrile and in buffered water $\mathrm{HNT} / \mathrm{AH}_{2}$ was tested at three different concentrations and afforded rate constants $k_{\text {inh }}$ for the trapping of peroxyl radicals that were close to those recorded for pristine $\mathrm{AH}_{2}$. In dry acetonitrile $k_{\text {inh }}$ was somewhat lower than that recorded for pristine $\mathrm{AH}_{2}$, possibly due to the too slow a release of $\mathrm{AH}_{2}$ in solution, and was also impaired by the modest solubility of ascorbic acid in the organic solvent. Indeed, upon addition of $1 \%$ water to the solvent to simulate "standard" acetonitrile and aid the release/solubilisation of $\mathrm{AH}_{2}$, the recorded $k_{\text {inh }}$ value increased significantly (by about six-fold) surpassing the value recorded for pristine $\mathrm{AH}_{2}$ under the same settings (see also Table S4). In buffered water $k_{\text {inh }}$ for $\mathrm{HNT} / \mathrm{AH}_{2}$ was indistinguishable from that recorded for pristine $\mathrm{AH}_{2}$. More interestingly, however, compared to experiments with equivalent total amounts of $\mathrm{AH}_{2}$ in solution, $\mathrm{HNT} / \mathrm{AH}_{2}$ had significantly higher stoichiometric factor both in acetonitrile and in water, being able to apparently trap more radicals per molecule of $\mathrm{AH}_{2}$ released in solution as can be seen from visual comparison of autoxidations inhibited by $\mathrm{AH}_{2}$ in solution (Figure 4A,B), or by equivalents amounts loaded into HNT (Figure 4C,D). Quantitative data are collected in Table 2 and in Table S4.

Table 2. Antioxidant activity: rate constant for the reaction with ROO• radicals, $k_{\text {inh }}$, measured in inhibited autoxidation experiments at $303 \mathrm{~K}$ (mean $\pm \mathrm{SD}, N=3$ ). The number of radicals trapped by

\begin{tabular}{|c|c|c|c|c|c|c|}
\hline \multirow{2}{*}{ Sample } & \multicolumn{2}{|c|}{$\mathrm{MeCN}^{1}$} & \multicolumn{2}{|c|}{ MeCN + 1\% Water ${ }^{1}$} & \multicolumn{2}{|c|}{ Buffer $\mathrm{pH}=7.4^{2}$} \\
\hline & $k_{\mathrm{inh}} / \mathrm{M}^{-1} \mathrm{~s}^{-1}$ & $n$ & $k_{\mathrm{inh}} / \mathrm{M}^{-1} \mathrm{~s}^{-1}$ & $n$ & $k_{\mathrm{inh}} / \mathrm{M}^{-1} \mathrm{~s}^{-1}$ & $n$ \\
\hline HNT & No inhib & / & No inhib & / & No inhib & / \\
\hline $\mathrm{AH}_{2}$ & $(2.5 \pm 0.5) \times 10^{4}$ & Figure $5 \mathrm{~A}$ & $(3.1 \pm 0.5) \times 10^{4}$ & Figure $5 \mathrm{~A}$ & $(1.7 \pm 0.2) \times 10^{6}$ & Figure 5B \\
\hline $\mathrm{AH}_{2}+\mathrm{HNT}$ & $(1.5 \pm 0.3) \times 10^{4}$ & Figure 5A & $(3.5 \pm 0.5) \times 10^{4}$ & Figure $5 \mathrm{~A}$ & $(1.5 \pm 0.2) \times 10^{6}$ & Figure 5B \\
\hline $\mathrm{HNT} / \mathrm{AH}_{2}{ }^{3}$ & $(8 \pm 1) \times 10^{3}$ & Figure $5 \mathrm{~A}^{4}$ & $\left(5.1 \pm \underset{5}{0.5)} \times 10^{4}\right.$ & Figure $5 A^{4}$ & $(1.4 \pm 0.3) \times 10^{6}$ & Figure $5 B^{6}$ \\
\hline
\end{tabular}
each antioxidant molecule, $n$, obtained from the same experiments, is shown in Figure 5 and reported numerically in the supporting information.

${ }^{1}$ Experiment performed with Cumene $1.8 \mathrm{M}$, AIBN $50 \mathrm{mM} .{ }^{2}$ Experiment performed in phosphate buffer $0.1 \mathrm{M}$ $\mathrm{pH}=7.4$, THF $3.1 \mathrm{M}$, AAPH $25 \mathrm{mM} .{ }^{3}$ Apparent inhibition constant. ${ }^{4}$ Experiments performed with [HNT $/ \mathrm{AH}_{2}$ ] values of $0.095,0.18$ and $0.30 \mathrm{mg} / \mathrm{mL}$, corresponding to $\left[\mathrm{AH}_{2}\right]$ values of $1.4 \times 10^{-5} \mathrm{M}, 2.5 \times 10^{-5} \mathrm{M}$ and $4.2 \times 10^{-5} \mathrm{M}$, respectively. ${ }^{5}$ Experiment performed with Styrene $4.3 \mathrm{M}$, AIBN $50 \mathrm{mM}$. ${ }^{6}$ Experiments performed with [HNT/ $\mathrm{AH}_{2}$ ] values of $0.16,0.31$, and $0.46 \mathrm{mg} / \mathrm{mL}$, corresponding to $\left[\mathrm{AH}_{2}\right]$ values of $2.1 \times 10^{-5} \mathrm{M}, 4.0 \times 10^{-5} \mathrm{M}$, and $6.0 \times 10^{-5} \mathrm{M}$, respectively. 

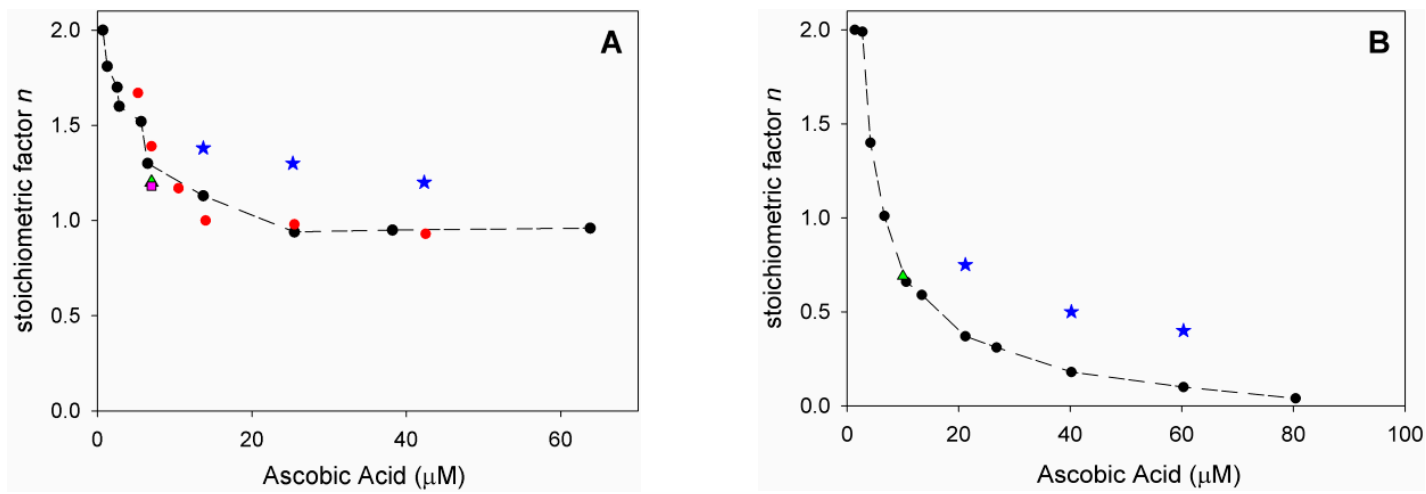

Figure 5. Variation of stoichiometric factor $n$ : (A) during the autoxidation of Cumene $(1.8 \mathrm{M})$ initiated by AIBN $(0.05 \mathrm{M})$ in acetonitrile at $30^{\circ} \mathrm{C}$ (red), and upon addition of: $1 \%$ water (black), HNTs $0.25 \mathrm{mg} / \mathrm{mL}$ (green), $1 \%$ water and HNTs $0.25 \mathrm{mg} / \mathrm{mL}$ (pink) inhibited by variable amount of $\mathrm{AH}_{2}\left(7.0 \times 10^{-7} \mathrm{M}\right.$ to $6.4 \times 10^{-5} \mathrm{M}$, red, black, green, and pink), or inhibited by $\mathrm{HNT} / \mathrm{AH}_{2}$ (blue); (B) during the autoxidation of THF $(3.1 \mathrm{M})$ initiated by AAPH $(25 \mathrm{mM})$ in phosphate buffer $0.1 \mathrm{M} \mathrm{pH}=7.4$ at $30^{\circ} \mathrm{C}$ (black) and upon addition of HNTs $0.25 \mathrm{mg} / \mathrm{mL}$ (green), inhibited by variable amount of antioxidant $\mathrm{AH}_{2}\left(1.4 \times 10^{-6} \mathrm{M}\right.$ to $8.1 \times 10^{-5} \mathrm{M}$, black and green) or inhibited by $\mathrm{HNT} / \mathrm{AH}_{2}$ (blue).

In acetonitrile the stoichiometric factor $n$ was higher, on average, $131 \%$ compared to pristine $\mathrm{AH}_{2}$ (Figure 5A), while in buffered water the advantage of $\mathrm{HNT} / \mathrm{AH}_{2}$ was even more striking, with higher $n$ values being as much as $400 \%$ (on average $290 \%$, three-fold) the value recorded for $\mathrm{AH}_{2}$ (Figure $5 \mathrm{~B}$ ). This excellent result is particularly important in buffered water (i.e., at close to physiological settings) as it completely subverts the scenario shown by $\mathrm{AH}_{2}$, caused by its competing reaction with oxygen (vide supra). In order to clarify the role of $\mathrm{HNT}$ on the antioxidant reactivity of $\mathrm{AH}_{2}$, parallel experiments were performed by adding, together, both pristine $\mathrm{AH}_{2}$ and pristine $\mathrm{HNT}$ in the autoxidising mixture. The mixture afforded antioxidant performance very similar to that of $\mathrm{AH}_{2}$ alone, and much lower than that recorded for composite HNT / $\mathrm{AH}_{2}$ (Table 2 and Table S4). This clearly indicates that the presence of halloysite nanotubes, per se, does alter the chemistry of ascorbic acid; therefore, the higher antioxidant performance of $\mathrm{HNT} / \mathrm{AH}_{2}$ can entirely be attributed to the slower progressive release of $\mathrm{AH}_{2}$ in solution as it is consumed by quenching peroxyl radicals. This will maintain lower concentration of ascorbate at any time, slowing down its side reactions with dioxygen (Equations (10) and (17), thereby decreasing both the unproductive depletion of antioxidant and its competing pro-oxidant behaviour. This explanation is supported by the stability studies on pristine $\mathrm{AH}_{2}$ (vide supra) that showed first-order dependence of the rate of degradation on its concentration. Additionally, $\mathrm{AH}_{2}$ is stabilized from oxidation as long as it is in the HNT lumen.

It should be noted that improved antioxidant performance of composite or hybrid nanoantioxidants is a rather rare achievement and typically their antioxidant performance is lower, or similar to the corresponding native small-molecule antioxidant. For instance, some of us recently found that HNT carrying curcumin on the outer surface had significantly lower efficiency in trapping peroxyl radicals that native curcumin, both in polar and apolar solution [29]; similarly, it has been shown that both HNT grafted with Trolox on the outer surface and HNT loaded with quercetin in the inner lumen had lower efficiency in trapping both peroxyl radicals and DPPH• radical than native Trolox and quercetin, respectively [33]. Such findings are not limited to halloysite: for instance, it was shown that metal nanoparticles decorated with Trolox trapped peroxyl radicals with a stoichiometric factor about halved with respect to Trolox itself [53]; similarly, the DPPH• radical scavenging activity of $\mathrm{SiO}_{2}$ nanoparticles functionalized with gallic acid depended on particle size but was generally lower than that of native gallic acid [54]. On the other hand, self-assembled polymer/iron/tannic acid nanoparticles had antioxidant activity in vitro similar to native tannic acid [55]. There is no previous study in the literature comparing the direct antioxidant activity of ascorbic acid with that of any nano-sized composite, however, the $\mathrm{DPPH} \bullet$ radical scavenging activity of $\mathrm{SiO}_{2} /$ ascorbate 
nanoparticles were no better than that of ascorbate itself [26]. The decreased or not improved antioxidant performance of hybrid nanomaterials should not be read as diminishing their value, as they typically outperform the small-molecule antioxidants in other respects, such as controlled or targeted delivery. However, this scenario renders our current findings even more interesting.

The method used here to investigate $\mathrm{HNT} / \mathrm{AH}_{2}$ represents a valuable tool to achieve physical understanding of the factors affecting the antioxidant behaviour of hybrid biomaterials by allowing their reaction with peroxyl radicals be studied on quantitative grounds.

Although $\mathrm{HNT} / \mathrm{AH}_{2}$ does not reach the ideal stoichiometry of peroxyl radical trapping of $n=2$, and there is still margin for improvement, our results demonstrate that protection of ascorbate into HNT lumen represents an unusually promising strategy, paving the way to the development of even more performing biomimetic antioxidant materials.

\section{Conclusions}

The good antioxidant behaviour of ascorbic acid either in organic or aqueous environment is largely hampered by its instability in solution, in the presence of atmospheric oxygen. Competitive oxidative degradation has apparent first-order dependence on the concentration of $\mathrm{AH}_{2}$ and is particularly remarkable under pseudo-physiologic conditions ( $\mathrm{pH} 7.4$ buffered water) where the stoichiometric factor for peroxyl radical trapping drops from two peroxyl radicals per molecule of $\mathrm{AH}_{2}$ to less than 0.1 on increasing the antioxidant concentration in the range $1-80 \mu \mathrm{M}$. Selective loading of $\mathrm{AH}_{2}$ in the inner lumen of HNT allows the creation of a composite nanomaterial that improves $\mathrm{AH}_{2}$ stability and makes $\mathrm{HNT} / \mathrm{AH}_{2}$ able to slowly release $\mathrm{AH}_{2}$ in solution in the reduced form. $\mathrm{HNT} / \mathrm{AH} 2$ proved to be a very effective antioxidant form of ascorbic acid, particularly suitable for applications in water solution under physiological settings where the antioxidant performance was enhanced on average by three-fold in the protection of a standard organic substrate. To the best of our knowledge, current results are unprecedented with respects to the various strategies aimed at improving the stability or the performance of ascorbic acid, including those based on its synthetic modification, and indicate that protection of $\mathrm{AH}_{2}$ in the lumen of inert nanotubes could be a most valuable strategy to develop optimized materials able to deliver the full properties of ascorbic acid in a stable and practical form.

Supplementary Materials: The following are available online at http:/ / www.mdpi.com/2076-3921/8/2/30/s1, Figure S1. Thermograms of HNT, HNT $/ \mathrm{AH}_{2}$, and $\mathrm{HNT}+\mathrm{AH}_{2}$ mixtures in air, Figure S2. Spectrophotometric analysis of $\mathrm{AH}_{2}$ release from $\mathrm{HNT} / \mathrm{AH}_{2}$ in acetonitrile, Figure S3. Spectrophotometric analysis of $\mathrm{AH}_{2}$ release from $\mathrm{HNT} / \mathrm{AH}_{2}$ in buffered water, Figure S4. Ascorbic acid decay in methanol at $25^{\circ}$, Figure S5. Ascorbic acid decay in buffered water at $25^{\circ}$, Figure S6. Ascorbic acid decay in acetonitrile at $25^{\circ}$, Figure S7. UV-VIS spectra of DPPH• reacting with $\mathrm{AH}_{2}$ and $\mathrm{HNT} / \mathrm{AH}_{2}$, Table S1. Release of ascorbic acid $\left(\mathrm{AH}_{2}\right)$ from $\mathrm{HNT} / \mathrm{AH} 2$ in acetonitrile at $298 \mathrm{~K}$, Table S2. Release of ascorbic acid $\left(\mathrm{AH}_{2}\right)$ from $\mathrm{HNT} / \mathrm{AH}_{2}$ in buffered water at $298 \mathrm{~K}$, Table S3. Summary of $\mathrm{AH}_{2}$ release from $\mathrm{HNT} / \mathrm{AH}_{2}$, Table S4: Stochiometric factors for peroxyl radical trapping by $\mathrm{AH}_{2}$ and HNT $/ \mathrm{AH}_{2}$, Scheme S1. Reaction of ascorbic acid $\left(\mathrm{AH}_{2}\right)$ with DPPH• radical.

Author Contributions: All authors contributed to the project; the main contributions are specified as follows: conceptualization: L.V. and R.A.; methodology: A.B., T.B., L.M., and E.D.; investigation: A.B., T.B., L.M., E.D., and R.A.; resources: L.V., R.A., T.B., and L.M.; writing-original draft preparation: L.V.; editing: A.B.; supervision: A.B. and R.A.; project administration: L.V.; funding acquisition: L.V. and R.A.

Funding: This work was supported by a grant to L.V. and R.A. from the University of Bologna (FARB project FFBO123154).

Conflicts of Interest: The authors declare no conflict of interest.

\section{References}

1. Halliwell, B.; Gutteridge, J.M.C. Free Radicals in Biology and Medicine, 5th ed.; Oxford University Press: Oxford, UK, 2015; ISBN 978-0-1987-1748-5.

2. Niki, E. Action of ascorbic acid as a scavenger of active and stable oxygen radicals. Am. J. Clin. Nutr. 1991, 54, 1119S-1124S. [CrossRef] [PubMed] 
3. Harris, J.R. Ascorbic Acid: Biochemistry and Biomedical Cell Biology, in Subcellular Biochemistry; Springer: New York, NY, USA, 1996; Volume 25, ISBN 978-1-4613-0325-1.

4. Jacob, R.A.; Sotoudeh, G. Vitamin C function and status in chronic disease. Nutr. Clin. Care 2002, 5, 66-74. [CrossRef] [PubMed]

5. Vitamin C Fact Sheet for Consumers. Available online: https://ods.od.nih.gov/factsheets/VitaminCConsumer/ (accessed on 1 July 2017).

6. Hathcock, J.N.; Azzi, A.; Blumberg, J.; Bray, T.; Dickinson, A.; Frei, B.; Jialal, I.; Johnston, C.S.; Kelly, F.J.; Kraemer, K.; et al. Vitamins $\mathrm{E}$ and $\mathrm{C}$ are safe across a broad range of intakes. Am. J. Clin. Nutr. 2005, 81, 736-745. [CrossRef] [PubMed]

7. Mason, S.A.; Baptista, R.; Della Gatta, P.A.; Yousif, A.; Russell, A.P.; Wadley, G.D. High-dose vitamin C supplementation increases skeletal muscle vitamin C concentration and SVCT2 transporter expression but does not alter redox status in healthy males. Free Radic. Biol. Med. 2014, 77, 130-138. [CrossRef] [PubMed]

8. Iqbal, K.; Khan, A.; Khattak, M.M.A.K. Biological significance of ascorbic acid (Vitamin C) in human health-A Review. Pak. J. Nutr. 2004, 3, 5-13.

9. Du, J.; Cullen, J.J.; Buettner, G.R. Ascorbic acid: Chemistry, biology and the treatment of cancer. Biochim. Biophys. Acta 2012, 1826, 443-457. [CrossRef]

10. Young, J.I.; Zuchner, S.; Wang, G. Regulation of the Epigenome by Vitamin C. Annu. Rev. Nutr. 2015, 35, 545-564. [CrossRef]

11. Pisoschi, A.M.; Pop, A. The role of antioxidants in the chemistry of oxidative stress: A review. Eur. J. Med. Chem. 2015, 97, 55-74. [CrossRef]

12. Valgimigli, L.; Bartolomei, D.; Amorati, R.; Haidasz, E.; Hanthorn, J.J.; Nara, S.J.; Brinkhorst, J.; Pratt, D.A. 3-Pyridinols and 5-pyrimidinols: Tailor-made for use in synergistic radical-trapping co-antioxidant systems. Beilstein J. Org. Chem. 2013, 9, 2781-2792. [CrossRef]

13. Bowry, V.W.; Ingold, K.U. The unexpected role of vitamin E ( $\alpha$-tocopherol) in the peroxidation of human low-density lipoprotein. Acc. Chem. Res. 1999, 32, 27-34. [CrossRef]

14. Yuan, J.-P.; Chen, F. Degradation of ascorbic acid in aqueous aolution. J. Agric. Food Chem. 1998, 46, 5078-5082. [CrossRef]

15. Gallarate, M.; Carlotti, M.E.; Trotta, M.; Bovo, S. On the stability of ascorbic acid in emulsified systems for topical and cosmetic use. Int. J. Pharm. 1999, 188, 233-241. [CrossRef]

16. Sapeia, L.; Hwa, L. Study on the Kinetics of Vitamin C Degradation in Fresh Strawberry Juices. Procedia Chem. 2014, 9, 62-68. [CrossRef]

17. Burdurlu, H.S.; Koca, N.; Karadeniz, F. Degradation of vitamin C in citrus juice concentrates during storage. J. Food Eng. 2006, 74, 211-216. [CrossRef]

18. Amorati, R.; Baschieri, A.; Morroni, G.; Gambino, R.; Valgimigli, L. Peroxyl radical reactions in water solution: A gym for proton-coupled electron-transfer theories. Chem. Eur. J. 2016, 22, 7924-7934. [CrossRef] [PubMed]

19. Haidasz, E.A.; Van Kessel, A.T.M.; Pratt, D.A. A Continuous visible light spectrophotometric approach to accurately determine the reactivity of radical-trapping antioxidants. J. Org. Chem. 2016, 81, 737-744. [CrossRef] [PubMed]

20. Han, R.; Liu, L.; Li, J.; Du, G.; Chen, J. Functions, applications and production of 2-O-D-glucopyranosyl-L-ascorbic acid. Appl. Microbiol. Biotechnol. 2012, 95, 313-320. [CrossRef]

21. Špiclin, P.; Homar, M.; Zupančič-Valant, A.; Gašperlin, M. Sodium Ascorbyl phosphate in topical microemulsions. Int. J. Pharm. 2003, 256, 65-73. [CrossRef]

22. Amorati, R.; Pedulli, G.F.; Valgimigli, L. Kinetic and thermodynamic aspects of the chain-breaking antioxidant activity of ascorbic acid derivatives in non-aqueous media. Org. Biomol. Chem. 2011, 9, 3792-3800. [CrossRef]

23. Špiclin, P.; Gašperlin, M.; Kmetec, V. Stability of ascorbyl palmitate in topical microemulsions. Int. J. Pharm. 2001, 222, 271-279. [CrossRef]

24. Maia Campos, P.M.B.G.; Gianeti, M.D.; Camargo, F.B., Jr.; Gaspar, L.R. Application of tetra-isopalmitoyl ascorbic acid in cosmetic formulations: Stability studies and in vivo efficacy. Eur. J. Pharm. Biopharm. 2012, 82, 580-586. [CrossRef] [PubMed]

25. Cheng, W.; Compton, R.G. Investigation of single-drug-encapsulating liposomes using the nano-impact method. Angew. Chem. Int. Ed. 2014, 53, 13928-13930. [CrossRef] [PubMed] 
26. Yang, J.-H.; Lee, S.-Y.; Han, Y.-S.; Park, K.-C.; Choy, J.-H. Efficient transdermal penetration and improved stability of L-ascorbic acid encapsulated in an inorganic nanocapsule. Bull. Korean Chem. Soc. 2003, 24, 499-503.

27. Lvov, Y.M.; Shchukin, D.G.; Mohwald, H.; Price, R.R. Halloysite clay nanotubes for controlled release of protective agents. ACS Nano 2008, 2, 814-820. [CrossRef] [PubMed]

28. Massaro, M.; Lazzara, G.; Milioto, S.; Noto, R.; Riela, S. Covalently modified halloysite clay nanotubes: synthesis, properties, biological and medical applications. J. Mater. Chem. B 2017, 5, 2867-2882. [CrossRef]

29. Massaro, M.; Amorati, R.; Cavallaro, G.; Guernelli, S.; Lazzara, G.; Milioto, S.; Noto, R.; Poma, P.; Riela, S. Direct chemical grafted curcumin on halloysite nanotubes as dual-responsive prodrug for pharmacological applications. Colloid Surf. B 2016, 140, 505-513. [CrossRef]

30. Fu, Y.; Zhao, D.; Yao, P.; Wang, W.; Zhang, L.; Lvov, Y. Highly Aging-resistant elastomers doped with antioxidant-loaded clay nanotubes. ACS Appl. Mater. Interfaces 2015, 7, 8156-8165. [CrossRef]

31. Massaro, M.; Piana, S.; Colletti, C.G.; Noto, R.; Riela, S.; Baiamonte, C.; Giordano, C.; Pizzolanti, G.; Cavallaro, G.; Milioto, S.; et al. Multicavity halloysite-amphiphilic cyclodextrin hybrids for co-delivery of natural drugs into thyroid cancer cells. J. Mater. Chem. B 2015, 3, 4074-4081. [CrossRef]

32. Vergaro, V.; Lvov, Y.M.; Leporatti, S. Halloysite clay nanotubes for resveratrol delivery to cancer cells. Macromol. Biosci. 2012, 12, 1265-1271. [CrossRef]

33. Massaro, M.; Riela, S.; Guernelli, S.; Parisi, F.; Lazzara, G.; Baschieri, A.; Valgimigli, L.; Amorati, R. A synergic nanoantioxidant based on covalently modified halloysite-trolox nanotubes with intra-lumen loaded quercetin. J. Mater. Chem. B 2016, 4, 2229-2241. [CrossRef]

34. Fakhrullina, G.I.; Akhatova, F.S.; Lvov, Y.M.; Fakhrullin, R.F. Toxicity of halloysite clay nanotubes in vivo: A caenorhabditis elegans study. Environ. Sci. Nano 2015, 2, 54-59. [CrossRef]

35. Valgimigli, L.; Bascheri, A.; Amorati, R. Antioxidant sctivity of nanomaterials. J. Mater. Chem. B 2018, 6, 2036-2051. [CrossRef]

36. Amorati, R.; Baschieri, A.; Valgimigli, L. Measuring antioxidant activity in bioorganic samples by the differential oxygen uptake apparatus: recent advances. J. Chem. 2017, 2017, 6369358. [CrossRef]

37. Amorati, R.; Valgimigli, L.; Panzella, L.; Napolitano, A.; d'Ischia, M. 5-S-Lipoylhydroxytyrosol, a multidefense antioxidant featuring a solvent-tunable peroxyl radical-scavenging 3-thio-1,2dihydroxybenzene motif. J. Org. Chem. 2013, 78, 9857-9864. [CrossRef] [PubMed]

38. Amorati, R.; Lynett, P.T.; Valgimigli, L.; Pratt, D.A. The reaction of sulfenic acids with peroxyl radicals: insights into the radical-trapping antioxidant activity of plant-derived thiosulfinates. Chem. Eur. J. 2012, 18, 6370-6379. [CrossRef] [PubMed]

39. Valgimigli, L.; Lucarini, M.; Peduli, G.F.; Ingold, K.U. Does $\beta$-carotene really protect vitamin E from oxidation? J. Am. Chem. Soc. 1997, 119, 8095-8096. [CrossRef]

40. Lucarini, M.; Peduli, G.F.; Valgimigli, L. Do peroxyl radicals obey the principle that kinetic solvent effects on $\mathrm{H}$-atom abstraction are independent of the nature of the abstracting radical? J. Org. Chem. 1998, 63, 4497-4499. [CrossRef]

41. Lucarini, M.; Pedulli, G.F.; Valgimigli, L.; Amorati, R.; Minisci, F. Thermochemical and kinetic studies of a bisphenol antioxidant. J. Org. Chem. 2001, 66, 5456-5462. [CrossRef] [PubMed]

42. Hanthorn, J.J.; Valgimigli, L.; Pratt, D.A. Incorporation of ring nitrogens into diphenylamine antioxidants: Striking a balance between reactivity and stability. J. Am. Chem. Soc. 2012, 134, 8306-8309. [CrossRef] [PubMed]

43. Benelli, T.; Mazzocchetti, L.; D’Angelo, E.; Lanzi, M.; Saraga, F.; Sambri, L.; Franchini, M.C.; Giorgini, L. New nitrogen-rich heterocycles for organo-modified bentonites as flame retardant fillers in epoxy resin nanocomposites. Polym. Eng. Sci. 2017, 57, 621-630. [CrossRef]

44. Biddeci, G.; Cavallaro, G.; Di Blasi, F.; Lazzara, G.; Massaro, M.; Milioto, S.; Parisi, F.; Riela, S.; Spinelli, G. Halloysite nanotubes loaded with peppermint essential oil as filler for functional biopolymer film. Carbohydr. Polym. 2016, 152, 548-557. [CrossRef] [PubMed]

45. Zheng, H.; Cheng, H.; Zhou, L.; Ye, Y.; Chen, J. Intercalated polyaniline/halloysite nanocomposites by a solvent-free mechanochemical method. Nano 2016, 11, 1650112. [CrossRef]

46. Cavallaro, G.; Lazzara, G.; Milioto, S.; Palmisano, G.; Parisi, F. Halloysite nanotube with fluorinated lumen: Non-foaming nanocontainer for storage and controlled release of oxygen in aqueous media. J. Colloid Interfaces Sci. 2014, 417, 66-71. [CrossRef] [PubMed] 
47. Bradshaw, M.P.; Barril, C.; Clark, A.C.; Prenzler, P.D.; Scollary, G.R. Ascorbic acid: A review of its chemistry and reactivity in relation to a wine environment. Crit. Rev. Food Sci. Nutr. 2011, 51, 479-498. [CrossRef] [PubMed]

48. Kimoto, E.; Tanaka, H.; Ohmoto, T.; Choami, M. Analysis of the transformation products of dehydro-L-ascorbic acid by ion-pairing high performance liquid chromatography. Anal. Biochem. 1993, 214, 38-44. [CrossRef] [PubMed]

49. Cabelli, D.E.; Blelskl, B.H.J. Kinetics and mechanism for the oxidation of ascorbic acid/ascorbate by $\mathrm{HO}_{2} / \mathrm{O}_{2}{ }^{-}$ radicals. A pulse radiolysis and stopped-flow photolysis study. J. Phys. Chem. 1983, 87, 1809-1812. [CrossRef]

50. Wilson, R.J.; Beezer, A.E.; Mitchell, J.C. A Kinetic study of the oxidation of L-ascorbic acid (vitamin C) in solution using an isothermal microcalorimeter. Thermochim. Acta 1995, 264, 27-40. [CrossRef]

51. Buettner, G.R. In the absence of catalytic metals ascorbate does not autoxidize at pH 7: Ascorbate as a test for catalytic metals. J. Biochem. Bioph. Meth. 1988, 16, 27-40. [CrossRef]

52. Robertson, G.L.; Samaniego, C.M.L. Effect of initial dissolved oxygen levels on the degradation of ascorbic acid and the browning of lemon juice during storage. J. Food Sci. 1986, 51, 184-187. [CrossRef]

53. Viglianisi, C.; Di Pilla, V.; Menichetti, S.; Rotello, V.M.; Candiani, G.; Malloggi, C.; Amorati, R. Linking an $\alpha$-tocopherol derivative to cobalt $(0)$ nanomagnets: Magnetically responsive antioxidants with superior radical trapping activity and reduced cytotoxicity. Chem. Eur. J. 2014, 20, 6857-6860. [CrossRef]

54. Deligiannakis, Y.; Sotiriou, G.A.; Pratsinis, S.E. Antioxidant and antiradical $\mathrm{SiO}_{2}$ nanoparticles covalently functionalized with gallic acid. ACS Appl. Mater. Interfaces 2012, 4, 6609-6617. [CrossRef] [PubMed]

55. Tang, C.; Amin, D.; Messersmith, P.B.; Anthony, J.E.; Prud'homme, R.K. Polymer directed self-assembly of pH-responsive antioxidant nanoparticles. Langmuir 2015, 31, 3612-3620. [CrossRef] [PubMed]

(C) 2019 by the authors. Licensee MDPI, Basel, Switzerland. This article is an open access article distributed under the terms and conditions of the Creative Commons Attribution (CC BY) license (http:/ / creativecommons.org/licenses/by/4.0/). 